\title{
Keel ruumis ja ruum keeles
}

\author{
TAURI TUVIKENE, MARI UUSKÜLA
}

Selle interdistsiplinaarse teemanumbri keskmes on ruumi mõiste ja ruumi keeleline väljendamine. Kui ühelt poolt on keel ruumist kõnelemise vahend, siis teisalt on see ise maailm, mis sisaldab arusaamu erinevatest ruumilistest aspektidest, mida muutes saab painutada ka mõtlemisviise. Ruumist kõneldakse oskus- ja argikeeles, erinevaid ruume kujutatakse kirjanduses ja ajakirjanduses, aga samal ajal kannab keel ise ruumilisi suhteid, mis maailmatunnetust struktureerivad. Kahtlemata on nn ruumiline pööre humanitaarteaduses aidanud kaasa ruumist mitmekesiselt mõtlemisele eri distsipliinides, lastes ruumi näha tähenduslikuna ja sotsiaalselt (seega ka keeleliselt) konstrueerituna, mitte lihtsalt raami või taustana (vt nt Kurg 2006). Samal ajal on kultuuriline pööre rõhutanud keele tähtsust ruumilistes distsipliinides (Sooväli 2008). Seega pole keele ja ruumi analüüs üks terviklik valdkond, kus saaks minna süvitsi ühe distsipliini sees.

Meie eesmärk ei ole öelda, et üks või teine teadus on ruumist ja keelest mõtlemises ilmtingimata jõudnud asjade tuumani. Püüamegi püsida distsipliinide kokkupuutepunktides. Kuigi keeleteadus tunneb kahtlemata kõige paremini keel(t)e sisemist loogikat ja semantilisi nüansse, nagu näitavad ka mitmed selle numbri artiklid, ei ole sellel distsipliinil keelest rääkimise ainuõigust. Sõnu ja mõisteid, keelelisi ruume ja kujutlusi uurivad ka humanitaaria teised harud, mistõttu keelest mõtlevad siin kogumikus keeleteadlaste kõrval nii inimgeograafid, haridusteadlased, kirjandus- ja tõlketeadlane kui ka filosoof. Teemanumbris püütaksegi ühendada humanitaarteadusi, mis on seni seisnud pigem üksteisest eraldi, kuna keskne küsimus jääb mitme eriala piirimaile (Repko 2016). Samuti tahtsime kokku tuua ruumiuuringute spetsialistid ja keeleteadlased, kes uurivad ruumikäsitlusi keeles. Kui esimesed tunnevad ennast ebamugavalt keeledetailide kohta midagi väites ja viimased satuvad harva ruumiuuringute mängumaale, siis teemanumbri artiklid püüdlevadki just valdkondade lõimimisele, käsitledes metafoore, maastikke keeles, grammatilisi ja leksikaalseid ruumisuhteid ja ruumidiskursusi eri kontekstis, ruumiga seotud sõnamoodustuslikke aspekte ja sõnade päritolu. Iga selline kogumik on kahtlemata piiratud nii teemade valiku kui ka autorite poolest, kajastades toimetajate subjektiivseid ja erialaseid eelistusi, ent pakub siiski ühe võimaliku sissevaate sellesse, kuidas humanitaarteadlased mõtlevad keele ja ruumi kokkupuudetest.

Teemanumber lähtub kahe teadlase - keeleteadlase ja inimgeograafi - huvidest. Kuigi keel on iga geograafi jaoks esiplaanil näiteks juba sõnade maastik, ruum, koht või linn tähendusväljade ja mõistete piiritlemise juures, inspireeris üht koostajat ikkagi konkreetne sõna: liikleja (vt Tuvikene, siin numbris). Ühes sõnas on peidus terve tänavaruumis liikumisega seonduv mõistevõrgustik. Keeleteadlasest koostaja jaoks on keel muidugi alati kesksel kohal, ent keelelised ruumiterminid 
ja ruumisuhted vajasid lähemat uurimist. Ühtlasi sai selles koostöös selgeks, et kui keeleteadusele on omane pigem kitsas valdkondlikkus, siis põhjalik ruumi ja keele kokkutoomine eeldab distsiplinaarset mitmekesisust. Seda võib muidugi saavutada mitmeti: mitu eriala võib kompotiks keeta juba üksikus artiklis (nt Uusküla jt siin numbris). Ent kuna hea toit ei tähenda ilmtingimata seda, et kõik komponendid tuleb omavahel kokku segada - hea tulemuse saab ka neid ühele taldrikule lähestikku asetades -, siis otsustasimegi keelest ja ruumist maitsva roa serveerida sellel Keele ja Kirjanduse numbri taldrikul. Eeltööks oli 21. novembril 2019. aastal toimunud seminar Tallinna Ülikoolis, kus peeti ettekanded enamiku siin esindatud artiklite teemal ning iga esineja erialane pädevus sai tuge teiste distsipliinide esindajate arutelust ja tagasisidest. Sissejuhatuses selgitame, miks me need keelt alla viivad komponendid ühele taldrikule panime, ja pakume välja oma arusaama sellest, mis maitse nii tekib.

Esiteks kirjeldame, milline on ruumiuuringute ruumikäsitlus ja mis koht võiks selles käsitluses olla keelel. Teiseks võtame ette keeleteaduse pika ruumiuurimise traditsiooni ja vaatame, kuidas see aitab meid lähemale terviklikule keele ja ruumi arusaamale. Kõige lõpuks aga käime läbi teemanumbri artiklid ja visandame neist võrsuva arusaama keelest ja ruumist. Kuigi iga tekst jääb paljuski truuks oma distsipliinile, siis üheskoos annavad need edasi seda, kuidas humanitaarteadused laiemalt ruumi käsitlevad.

\section{Keel ja ruum ruumiteaduses ja keeleteaduses}

Ruum on geograafias keskne, õigupoolest isegi distsipliini defineeriv mõiste. See ei tähenda, et mõiste tähendusvälja üle pidevalt vaieldaks, küll aga peab igas uurimuses kajastuma mingi arusaam ruumist. Üldiselt mõistetakse ruumi kolmes tähenduses (vt Jauhiainen 2005: 71-79). Esiteks, klassikaliselt on ruum mahuti, milles tegevused toimuvad. Sellisel juhul on oluline ruumi suurus, muud aspektid on vähetähtsad. Teiseks, veidi tihedamalt sisustatuna tähistab ruumi mõiste objektide suhteid: asjade vahel on nii ja nii palju ruumi, mõne vahel rohkem, mõne vahel vähem. Kolmandaks mõistetakse ruumi ennast kui suhete süsteemi: ruumi õigupoolest ei olegi enne, kui erinevad elemendid ei ole paigutunud vastastikku nii, et seda ruumi tekitada (Massey 2005). Selles ruumis ei ole olulised mitte niivõrd piirid ega ruum objektide vahel, kuivõrd just objektide aktiivsed suhted ja vastastikune toimimine. Suur osa geograafiakirjandust (nt Lefebvre 1991; Harvey 2009 [1973]) käsitleb seda ruumisüsteemi ja sealseid suhteid aga kapitalistlikuna. Nõnda ei ole ruum geograafilises kirjanduses abstraktne taust, mille olemust keelesüsteemi kaudu uurida, vaid on konkreetselt sisustatud näiteks omandisuhete, kinnisvara ja linnaplaneerimisega (vt Roose jt, selles numbris). Nii mõistetuna tähendab keel ruumis maailmatunnetust, mis objektide suhteid ja toimimisi mitte ainult ei kirjelda, vaid ka suunab. „Kelle ees ja mille taga?" (vt Veismann, selles numbris) pole seega küsimus ainult abstraktsete ruumisuhete keelelisest väljendamisest, vaid sisaldab endas ka küsimusi võimusuhetest, traditsioonidest ja tavapraktikatest. 
Ruum on aga vaid üks ruumimõiste. Sellele lisanduvad pea sama tähtsana koht ja maastik, mis on ehk tavakasutuses sagedamadki kui ruum ise, eriti võrreldes eelmises lõigus kirjeldatud valdkondliku aruteluga. Ruum tavateadmises võib olla tõesti mahuti, tühimik (kus on veel veidi ruumi), samuti toa sünonüüm või kasutusel ilmaruumi tähenduses. Ühegagi neist pole aga geograafilises kirjanduses palju peale hakata. Ruumi nägemine suhete süsteemina eeldab abstraktset kontseptuaalset mõtlemist, mille tulemusena ka sõna ruum omandab teised tähendusvarjundid kui tavakeeles. Sõnaga koht kutsume eri asupaiku, millel on meie jaoks mingi tähendus, mis annab neile sageli ka nime (Oja 2000). Keel ja ruum on seega palju kohtunud ka kohanimede uuringus ehk toponüümikas, mis ühe onomastika aladistsipliinina uurib nende nimede ajaloolist arengut ja muutusi poliitilistes tõmbetuultes (Kallasmaa 1995, 2000). Maastik jällegi on sõna, mida tavakeeles kasutame, kirjeldamaks looduslikke paiku, mis pakuvad ka silmailu (vt Uusküla jt, selles numbris). Teaduskirjanduses vaieldakse mõistete ruum, koht ja maastik tähenduste ja nende piiride üle: see, milline termin domineerib mõtlemises, suunab ka uuringute rõhuasetusi. Kui sõnaga ruum kerkivad esiplaanile objektidevahelised suhted ja võimuküsimused, siis maastik tõmbab tähelepanu representatsioonidele ja erinevatele tajumisviisidele, koht tähendustele ja identiteedile.

Keel on kõigepealt ruumiliste nähtuste kirjeldamise vahend, mis loob oma tajusüsteemi. Sapiri-Whorfi hüpoteesi järgi loob keel suisa maailmatunnetust raamistava süsteemi (vt Kay, Kempton 1984): keelelise relativismi teooria kohaselt on meie maailmatunnetus üheselt seotud keelega (Lucy 1997). Samal ajal levivad eri keelevormid ruumis ja on seotud mitmete (ka keeruliste) (võimu)suhetega: piirid murrete ja keelte vahel, keelekasutus ruumis ja sellega seonduv, mida keelemaastike käsitlus puudutab (nt Landry, Bourhis 1997). Ruumilised erinevused omakorda kanduvad keelde: näiteks erinevad värvikäsitlused on kantud geograafilistest eripäradest (vt Oja 2000; Uusküla, Bimler 2016). Samuti on keel kahtlemata oluline diskursuste kujundajana, näiteks mõjutades ruumipraktikaid ruumikäsitluste diskursustes (vt nt Roose jt siin numbris; vt samuti õpi- ja õpperuumi käsitlusega seonduvat Aava jt; Põlda, Teidla-Kunitsõn).

Stephen Levinson on tabavalt öelnud, et ruumiline mõtlemine on tunginud kõikidesse mõttesfääridesse, kuna võimaldab aru saada abstraktsetest kontseptsioonidest. Sellele viitavad nii ruumisuhete grammatiseerumine kui ka ruumiliste metafooride rohkus keeles. Levinson toob näiteid ruumimetafooridest, millega väljendatakse aega (homne on veel ees, eilne on seljataga), inimsuhteid (kauged sugulased, lähedased sõbrad), sotsiaalset struktuuri (madal kast, kõrgest soost) ja palju muudki (sõprade ring, mõtlemise koht, ülev tunne, madal tung). (Levinson 1992: 5) Ruumisõnadel on palju tähenduskihte: ruumi kaudu rägitakse ajast ja seisundist, ruumisõnavara kasutades saab anda hinnanguid, väljendada suhteid, kirjeldada olukordi ja anda edasi abstraktseid mõtteid. Võib öelda, et ruum on paljuski maailma struktureerimise aluseks.

Kui vertikaalset ruumitelge (üleval-all) kodeeritakse üldjuhul eri keeltes sarnaselt, siis horisontaalsed teljed võivad lähtuda kas egotsentrilistest, objektikesksetest või absoluutsetest tähistest (Levinson, Wilkins 2006; sellest lähemalt vt Veismann, 
selles numbris). On selge, et ruumi kogemise viis lähtub paratamatult inimeste anatoomiast, neurofüsioloogiast ja kognitiivsest aparatuurist: me tajume ruumi oma tajuvõimaluste piires. See ei tähenda aga sugugi, et ruumi eri keeltes samamoodi kujutataks ja mõtestataks. Et teada saada, kuidas eri keelte kõnelejad ruumist räägivad, on korraldatud mitmesuguseid katseid. Need peaksid näitama, kas keeles domineeriv ruumikirjeldus kandub üle ka mittekeelelisele ruumitajule ehk kas keelekasutus mõjutab mõtlemist ja toetab seega keelelise relatiivsuse hüpoteesi. Asifa Majid ja tema kolleegid tegid katse, millesse valiti osalema erineva emakeelega inimesi. Kõigepealt jaotati keeled selle järgi, kas nende rääkijad kasutavad väikesemõõduliste ruumisuhete kirjeldamiseks absoluutset, objektikeskset või egotsentrilist viitesuhete võrgustikku. Seejärel näidati katses osalejatele laua peale paigutatud esemeid, pärast mida pöörati katsealused ümber, nii et laud jäi nende selja taha, esemed aga paluti asetada samamoodi. Pärast ümberpööramist on absoluutse ja suhtelise viitamissuhte võrgustiku kasutajatel täiesti erinev arusaam sellest, mida tähendab „sama asend". Esimesed paigutavad esemed ritta nii, et nende asend on sama absoluutsete orientiiride suhtes, teised lähtuvad enda vaatepunktist. Osalejad kasutasid oma emakeelele omaseid viitesuhete võrgustikke ehk katse näitas, et lingvistilised ja mittelingvistilised viitesuhete võrgustikud on omavahel vastavuses (Majid jt 2004: 110). Seega on keele ja ruumi suhted põnev uurimisallikas nii ühe keele sees kui ka keelte vahel, kuigi meie teemanumber keskendub põhiliselt eesti keelele ning keeltevahelised suhted jäävad uurimiseks mujale.

Peale keelelise relativismi on keele ja ruumi suhteid uuritud lingvistikas veel mitmest vaatepunktist. Lühiülevaate ruumi ja keele suhetest lingvistikas koos kirjandusviidetega annab Ann Veismanni artikli sissejuhatus ning me ei hakka siin kõiki keeleteaduslikke ruumikäsitlusi kordama. Eesti keeles on ruumisõnu ja -väljendeid uuritud just kognitiivse semantika ja grammatika seisukohast (Vainik 1995; Veismann 2009; Pajusalu jt 2013 jne). Kui ruumikäsitlusi on nii Eesti kui ka muu maailma keeleteaduses leida mitmeid, siis üks ruumiga seostuv mõiste - maastik - on alles hiljuti hakanud keeleteadlastele huvi pakkuma (Mark jt 2011; Burenhult, Levinson 2008). Siiski on ruumiliste suhete ja ruumimõistete keelelise loogika ja tähenduste uurimisel veel palju teha. See teemanumber on üksnes väike sissejuhatus.

\section{Ülevaade artiklitest}

Artiklid vaatlevad metafoorsete sõnade seotust füüsilise maailma nähtustega, oskussõnade jõudmist igapäevakeelde, uudissõnade tekke ja tähenduse omandamist kasutuses ning keeles edasi antavaid grammatilisi ruumisuhteid. Esimene artikkel keskendub ühele eesti keeles tavakasutuseski juurdunud ruumimõistele - maastik. Mari Uusküla, Anu Vau, Kaidi Rätsep ja Hannes Palang vaatlevad maastikku kui sõna, mis on kasutusel nii eriala- kui ka argikeeles, olles seega kategoriseeritud kahel viisil. Autorid annavad ülevaate maastikega seotud sõnade tajumisest küsitletute hulgas, luues nii maastiku keeletaksonoomilise süsteemi. Uusküla jt leiavad, et maastikust rääkimiseks kasutatav sõnavara viitab tavakeeles eelkõige loodusele ja loodus- 
nähtustele, linnad ja muu n-ö tehislik jääb pigem teisejärguliseks. Samuti on inimeste jaoks oluline just visuaalselt esilekerkiv, mistõttu näiteks mägi on enim maastikuga seostatud sõna uuringus osalejate seas, kuigi Eestis kõrgmägesid ei leidu. Taksonoomiad on argikasutuses ka paradoksaalsed: nii ei pruugi inimesed alati puude taga metsa näha, nimetades puud sagedamini maastikusõnana kui puude kogumit metsa.

Maastiku mõistega käib käsikäes ruumi mõiste, mida kasutatakse eriti linnaga seonduvalt sageli fraasis avalik ruum. Antti Roose, Helen Sooväli-Sepping ja Anni Müiuripeal tutvustavad seda kui Eesti erialakirjanduses tugevasti juurdunud sõnapaari, mille sisu on tavakasutajale üpriski selgusetu ja seetõttu problemaatiline. Artikkel kirjeldab mõiste tähendusvälja, nagu see paljuski avaneb angloameerika teaduskirjanduses, näidates ka mõiste juurdumist mõningates eesti keele kontekstides, nagu näiteks õigustekstides, arhitektuuris ja urbanistikas. Avalik ruum ja sellega käsikäes käiv mõiste avalik koht on saanud järjest olulisemaks arutelukohaks koos käesoleva aasta COVID-19 puhanguga: mis on need kohad, kus peab olema ettevaatlikum, desinfitseerima käsi, ehk isegi kandma maski, ja kus tuleb hoida kahemeetrist vahet?

Avaliku ruumi mõistega seostub see, kuidas inimene selles avalikus ruumis paikneb ja oma tegevust korraldab. Nii keskendub Tauri Tuvikene sõnadele liiklema ja liikleja (eelkõige just jalgsi käimise tähenduses). Tuues välja sõna liiklema ajaloo ja etümoloogia aspekte, otsib Tuvikene alternatiive sõna liikleja jalakäija tähenduses kasutamisele. Artikkel näitab, kuidas keelega võib n-ö süvitsi minna ka keelehuviline inimgeograaf, mitte vaid selleks spetsiaalse ettevalmistuse saanud lingvist. Kes siis on ikkagi liikleja, juhul kui ta käib jalgsi, ja millist rolli tema tegevus avalikus ruumis paiknemisel mängib ning milliseid praktikaid see loob, selgub artiklist.

Kaks järgmist artiklit vaatlevad samuti keele võimalusi mõtlemist mõjutada: seda, kuidas käsitletakse ruumi ülikoolikeskkonnas, millised erinevused on mõistetel ópperuum ja õpiruum ning kas ja kuidas peaks korrastama haridusmaastiku terminoloogiat. Muutused mõtlemises võiksid peegelduda ka keelekasutuse muutuses. Katrin Aava, Katrin Karu, Esta Kaal ja Mari Uusküla vaatlevadki õpikäsituses toimunud arusaamade muutuste võimalikku kandumist õppe- ja õpiruumide sõnalise kirjeldamise juurde. Õpi-(ruum) paneb keskmesse õppimise protsessi, samal ajal kui õppe-(ruum) viitab ikkagi õpetamisele kui tegevusele. Sõnade tavakasutus, nagu seda annavad edasi veebis leiduv pildimaterjal, tarbetekstid, aga ka meediakäsitlus, viitavad juba osaliselt ópiruumide sisustamisele uuenenud õpikäsituse keskselt, samas kui ópperuumide puhul on valdav lageda klassiruumi kujund, kus õpetaja teadmise õppijatele edasi kannab. Lõplik mõiste sisustamine, nagu Aava jt tunnistavad, sõltub aga sellest, milliste assotsiatsioonide ja konnotatsioonidega mõisted lõpuks kinnistuvad.

Kui Aava ja kolleegid püüavad avada õppe- ja õpiruumi mõistesisu ning soovitavad hoida need terminoloogiliselt lahus, läheb järgmine artikkel veelgi sügavamale ning uurib ruumi ülikooli sees, keskendudes haridusmuutuste ühele tahule ehk õppimise ruumile lähtuvalt üliõpilaste kogemustest. Halliki Põlda ja Gertha TeidlaKunitsõn alustavad isikliku kogemuse jagamisega, millest selgub, et igasugust õpet ülikooli mis tahes ruumis tajuvad üliõpilased siiski formaalõppena. Seega on ülikooli 
ruum seotud formaalsuse ja mitteformaalsuse käsitlusega. Diskursuseanalüüsi kasutades käsitleb artikkel üliõpilaste eneserefleksioonide ja fookusgrupi intervjuude põhjal hariduses valitsevaid (hierarhilisi) suhteid, kus õppimist kirjeldatakse kui teadmiste siirdamist õppejõult õppijale, olenemata haridusuuendusest, mille keskmes arvatakse olevat õppija. Peamiselt tõlgendatakse õpiruumi kolmemõõtmelisena: selles võib eristada nii füüsilist, sotsiaalset kui ka vaimset ruumi. Mõnevõrra kurb on tõdeda, et üliõpilased ei taju ülikooli ruume just õppimist toetavana, kuid täpsema ülevaate saab artiklist.

Kaks järgnevat artiklit keskenduvad konkreetselt keelesüsteemidele ja neis edasi antavatele ruumisuhetele erinevates grammatilistes keelekonstruktsioonides, kasutades korpuste keeleandmeid. Ann Veismann annab ülevaate sellest, kuidas käituvad eesti keeles kaassõnakolmikud ette, ees, eest ja taha, taga, tagant, mida ta nimetab EES-kaassõnadeks ja TAGA-kaassõnadeks. Kaassõnade kasutus on oluline seetõttu, et näitab, kuidas inimene ruumis orienteerub ning asjade asukohti kindlaks määrab. Veismanni artikkel loob elava kujutelma sellest, mida tähendab objektikeskne ja mida vaatajakeskne taustsüsteem. Sageli oleneb vaatajast, kas mingi objekt asub ees või taga, ning artiklis antakse ülevaade sellest, millistel objektidel on enamasti „kombeks” olla ees ja millistel taga. Veismann toob need sõnad välja semantiliste klasside kaudu.

Jane Klavan, Tanel Alumäe ja Arvi Tavast vaatlevad ruumilisust ja ruumisuhteid väliskohakäänetes. Artiklis analüüsitakse eesti keele väliskohakäändeid, mis väljendavad keele ja ruumi seoseid grammatiliselt, kasutuspõhise keeleteaduse kontekstis. Autorid annavad ülevaate, milliseid väliskohakäändeid kasutatakse enim tuntud raadiosaadetes „Huvitaja”, „Kultuurikaja” ja „Räägivad”, kasutades kirjeldavat statistikat. Lähenemise uudsus seisneb selles, et ühendatud on kasutuspõhine keeleteadus, poolspontaanne kõne ja kõne automaattuvastus, mis aitavad välja selgitada väliskohakäänete kasutussageduse ja väliskohakäänete semantilised funktsioonid. Kõige sagedamini kasutatakse raadiosaadetes adessiivi ehk alalütlevat käänet, kordades rohkem tehakse seda ka aja ja koha funktsioone väljendades kui alale- ja alaltütleva käände puhul.

Teemanumbri lõpetavad kaks artiklit, mille keskmes on keelesuhted ja keeleline taju kujundliku keele kasutusväljal ehk kirjanduses. Tõnu Viik tutvustab fenomenoloogilist ruumiloomet keeles. Ta argumenteerib Husserli fenomenoloogia võtmes, et kirjanduslike objektide ruumid tekivad teadvusesse mitte kujutluse, vaid keeletaju kaudu: lugeja kogeb seda, millest tekst kõneleb. Keeleline taju paikneb seega kusagil empiirilise taju ja kujutlusvõime vahepeal. Keeletaju ruumiloome toimib kujutluse ja konkreetse kirjelduse vahepeal, see taju on samaaegselt tühi ja konkreetne. Konkreetne objekt, näiteks maja, võib olla antud „ilma empiirilise, pildilise või kujutlusliku sisuta", ent ikka viidata süžees just ühele konkreetsele majale, milles näiteks tegelane elab ja mõnd tekstis kirjeldatud tegevust teeb.

Kui Viik vaatleb keeletaju üldisemalt erinevates kirjanduslikes kontekstides, siis Ülar Ploom läheb konkreetse teksti keelelise ruumitaju juurde ja võtab keskmesse just tähenduse ühest keeleruumist teise kandmise. Tema artikli keskmes on ruumitajude kultuurilise kodeerimisega seotud probleemid. Ruumi tekstiline edasi- 
andmine tugineb keelelis-kultuurilistele harjumustele, milles sotsiaalne ruum ja ruumitajud on kultuuriliselt kodeeritud. Desmond Hogani novelli „Viimane kord” objektiivses ja kehalises ruumis väljenduva sotsiaalse distantsi tõlkes edasiandmine osutus parajaks väljakutseks keele metafoorse laetuse tõttu. Raske on tõlkida kodeeritud sõnumeid ja tähendusvälju, mida teistes keeltes samal moel ei esine. Näiteks „embav mantel” või paiknemine „linna perimeetril”, linna ääres, aga mitte lihtsalt „äärelinnas”, on kujundid, mis novellis omasid tähendust konkreetses paigutuses ja erinevate kultuuriliste registrite taustal, ent tõlgituna sattusid teise tähendusvälja ja nõudsid tõlkijalt hoopis teistlaadi tähelepanu.

Kokkuvõttes annab see artiklikogum sissevaate keele ja ruumi läbipõimumisse ruumiliste mõistete käsitluses, ruumitaju ja -kogemuse suunamises ja metafoorses mõtlemises. Kindlasti väärib see lähenemine distsiplinaarset laiendamist ja teemaderingi suurendamist, võttes appi ka näiteks erinevate keelte arusaamad, keele ja võimu suhted ning muu sellise, kuid see jääb juba järgmiste kogumike teha.

Sissejuhatuse valmimist on toetanud Eesti Teadusagentuuri projekt „Maastikuline lähenemine rurbaansusele" (PRG 398).

\section{KIRJANDUS}

Burenhult, Niclas; Levinson, Stephen 2008. Language and landscape: A cross-linguistic perspective. - Language Sciences, kd 30, nr 2-3, lk 135-150.

Harvey, David 2009 [1973]. Social Justice and the City. Revised Edition. Athens-London: The University of Georgia Press.

Jauhiainen, Jussi S. 2005. Linnageograafia. Linnad ja linnauurimus modernismist postmodernismini. Tallinn: Eesti Kunstiakadeemia.

Kallasmaa, Marja 1995. Rahvaetümoloogia ja historismi printsiip onomastikas. - Keel ja Kirjandus, nr 11, lk 763-766.

Kallasmaa, Marja 2000. Koht, nimi ja kohanimi. - Koht ja paik I. (Proceedings of the Estonian Academy of Arts 8.) Toim Kaia Lehari, Virve Sarapik. Tallinn: Eesti Kunstiakadeemia, lk 112-119.

Kay, Paul; Kempton, Willett 1984. What is the Sapir-Whorf hypothesis? - American Anthropologist, kd 86, nr 1, lk 65-79.

Kurg, Andres 2006. Ruum, ca 1986. - Vikerkaar, nr 7-8, lk 89-104.

Landry, Rodrigue; Bourhis, Richard Y. 1997. Linguistic landscape and ethnolinguistic vitality: An empirical study. - Journal of Language and Social Psychology, kd 16, nr 1, lk 23-49.

Lefebvre, Henri 1991. The Production of Space. Oxford, UK-Cambridge, USA: Blackwell.

Levinson, Stephen C. 1992. Primer for the field investigation of spacial description and conception. - Pragmatics, kd 2, nr 1, lk 5-47.

Levinson, Stephen C.; Wilkins, David P. (toim) 2006. Grammars of Space. Explorations in Cognitive Diversity. Cambridge: Cambridge University Press.

Lucy, John A. 1997. Linguistic relativity. - Annual Review of Anthropology, kd 26, lk 291312. 
Majid, Asifa; Bowerman, Melissa; Kita, Sotaro; Haun, Daniel B. M.; Levinson, Stephen 2004. Can language restructure cognition? The case for space. - Trends in Cognitive Sciences, kd 8 nr 3, lk 108-114.

Mark, David M.; Turk, Andrew G.; Burenhult, Niclas; Seta, David 2011. Landscape in language. An introduction. - Landscape in Language. Transdisciplinary perspectives. Toim N. Burenhult, D. Seta, D. M. Mark, A. G. Turk. Amsterdam-Philadelphia: John Benjamins Publishing Company, lk 1-24.

Massey, Doreen 2005. For Space. Los Angeles-London-New Delhi-Singapore-Washington DC: Sage.

Oja, Vilja 2000. Mõiste, sõna ja koht. - Koht ja paik I. (Proceedings of the Estonian Academy of Arts 8.) Toim Kaia Lehari, Virve Sarapik. Tallinn: Eesti Kunstiakadeemia, lk 129-137.

Pajusalu, Renate; Kahusk, Neeme; Orav, Heili; Veismann, Ann; Vider, Kadri; Õim, Haldur 2013. The encoding of motion event in Estonian. - Motion Encoding in Language and Space. (Explorations in Language and Space.) Toim Mila Vulchanova, Emile van der Zee. Oxford University Press, lk 44-66.

Repko, Allen F. 2016. Interdisciplinary Research: Process and Theory. Thousand Oaks: SAGE Publications.

Sooväli, Helen 2008. Kultuurigeograafia. - Keel ja Kirjandus, nr 8-9, 1k 654-664.

Uusküla, Mari; Bimler, David 2016. From listing data to semantic maps: Cross-linguistic commonalities in cognitive representation of colour. - Folklore, kd 64, lk 57-90.

Vainik, Ene 1995. Eesti keele väliskohakäänete semantika: kognitiivse grammatika vaatenurgast. Tallinn: Eesti TA Eesti Keele Instituut.

Veismann, Ann 2009. Eesti keele kaas- ja määrsõnade semantika võimalusi. (Dissertationes linguisticae Universitatis Tartuensis 11.) Tartu: Tartu Ülikooli Kirjastus. 